J. Lake Sci. (湖泊科学), 2007, 19(4):359-366

http://www. jlakes.org. E-mail: jlakes@ niglas. ac.cn

(c) 2007 by Journal of Lake Sciences

\title{
浮游植物对湖泊水体生态重建的响应 以太湖五里湖大型围隔示范工程为例”
}

陈开 ${ }^{1,2}$, 周万平 ${ }^{1}$, 鲍传和 ${ }^{3}$, 胡洪云 ${ }^{1}$

( 1 : 中国科学院南京地理与湖泊研究所,南京 210008)

(2: 中国科学院研究生院,北京 100039)

( 3 : 安徽农业大学,合肥 230036)

摘 要: 根据太湖五里湖湾生态重建大型围隔示范工程的现场观测结果, 分析了湖泊生态重建措施对浮游植物的影响, 结 果显示: (1) 在生态重建的第一年, 尽管生态重建区内种植了大量水生植物, 水体氮磷含量也有较大幅度的下降, 水体透 明度也被提高了近一倍, 但是藻类却大量生长, 并暴发了蓝藻水华;第二年,生态重建区的环境条件逐渐对藻类(包括蓝藻 和其中的微囊藻) 产生了抑制作用, 开始出现藻类生物量下降趋势; 表明生态重建措施 (以水生植被重建为中心的生态系 统重建组合措施) 可以在较短时间内 (当年) 建立起一定规模的水生植物群落,有效降低水体氮磷营养盐, 提高水体透明 度,但要在较短时间内 (2 年内) 完善一个较大的水生态系统结构、有效降低藻类生物量 (特别是夏季)有一定困难. (2) 尽 管氮磷营养盐对水体藻类总量增加有较大影响, 但并不是蓝藻大量暴发的决定因素, 上行作用力对蓝藻的控制 ( bottom-up effort) 表现弱于下行作用力 (top-down effort). (3) 较低的 TN/TP 比值 (15.9-35.6, 平均 30.5) 既是蓝藻水华暴发的原因, 也是其作用的结果, 其可能有利于蓝藻的大量暴发. (4) 生态重建措施较大幅度地改善了水环境,但并没有显著提高藻类 多样性指数 (Shannon index), 因此, 单凭藻类多样性指数并不能完全反映水环境改善状况,在评价水环境质量方面需要结 合其它多种指标进行综合评估.

关键词 : 浮游植物; 生态重建; 蓝藻水华暴发; 太湖

\section{Response of phytoplankton to ecological restoration in eutrophic lakes: an experimental large enclosure in Wuli Lake, Lake Taihu}

\author{
CHEN Kaining ${ }^{1,2}$, ZHOU Wanping ${ }^{1}$, BAO Chuanhe ${ }^{3}$ \& HU Hongyun ${ }^{1}$ \\ (1: Nanjing Institute of Geography and Limnology, CAS, Nanjing 210008, P. R. China) \\ (2: Graduate School of Chinese Acdemy of Sciences, Beijing 100039, P. R. China) \\ (3: Anhui Agicultural University, Hefei 230036, P. R . China)
}

Abstract: Response of phytoplankton to ecological restoration was evaluated based on the results of an experimental large enclosure in eutrophic Wuli Lake of Lake Taihu, China. The results indicated that in the first year of restoration, algal biomass significantly increased, and cyanobacteria blooms broke out although the coverage of aquatic plant was up to 55\% ; TN and TP were significantly decreased, and secchi depth was enhanced by $100 \%$ or so. In the next year, algal growth, including cyanobacteria and Microcystis, was inhibited in certain extent with improvement of environment in enclosure compared with that in the lake area (outside enclosure, a control area). The result showed that response of phytoplankton to ecological restoration was a slow process. Higher TN and TP were not decisive factors for the breakout of cyanobacteria biomass though the increase of total algal biomass was caused by higher nutrition (TP). Bottom-up effort was weaker than top-down effort. The lower TN to TP ratio possibly facili-

* 国家重点基础研究发展项目 (973 计划) “湖泊富营养化过程和蓝藻水华暴发机理研究” (2002CB412307)、国家科 技部“十五”重大科技攻关项目（863）“太湖水污染控制与水体修复”(2002AA601013) 以及国家自然科学基金 (30670373) 联合资助. 2006-07-27 收稿;2006-11-22 收修改稿. 陈开宁, 男, 1964 年生, 博士生, 副研究员; Email:knchen@ niglas.ac.cn. 
tated cyanobacteria growth, which was the cause and the result of cyanobacteria growth. In addition, the algal diversity index (Shannon index) was not totally indicating aquatic environment improvement status. It was suggested that it needed to integrate many factors for evaluating the trend of ecosystem.

Keywords: Phytoplankton; ecological restoration; breakout of cyanobacteria blooms; Lake Taihu

水体富营养化是近半个多世纪以来重大的世界性水环境问题,并对人类社会 - 经济发展以及自然界生 产诸多负面影响. 由于氮磷等营养负荷的增加,水体富营养化的直接的表观现象是浮游植物 (藻类) 大量生 长, 特别是令人反感的蓝藻水华的暴发. 为了防治富营养化, 世界各国已进行大量研究与实践探索, 其中水 体生态恢复与重建是末端控制的主要措施之一, 其目标不仅在于降低水体氮磷负荷, 提高水体透明度和改 善景观, 而且还在于恢复与重建水域生态系统结构与良好的食物链网,增加或恢复生态系统功能, 提高系统 内部恢复力与阻滞力, 抑制浮游植物生长.

太湖五里湖生态重建示范工程是针对重富营养化水体进行的,采取了诸多技术措施的集成运用,并取 得了初步令人满意的效果 ${ }^{[1]}$. 但在生态重建计划实施过程中, 浮游植物的变化并没有因为水质的改善和水 生植被的初步建立而降低,其中隐含的科学问题引起了我们极大的兴趣. 本文依据五里湖生态重建大型围 隔的现场观测结果, 就生态重建初期对浮游植物生物量影响、浮游植物增长的阻滞因素、蓝藻水华暴发机制 等科学问题进行探讨, 目的是为控制水体富营养化,实现湖泊生态系统恢复提供理论依据.

\section{1 研究方法}

五里湖位于太湖西北部, 研究地点设在无锡五里湖湾的西部水域. 围隔建立在西五里湖南岸, 面积为 $10 \times 10^{4} \mathrm{~m}^{2}$, 内部种植有大量水生高等植物, 最大覆盖面积超过 $55 \%$. 围隔于 2004 年 3 月初建成完工, 围隔 材料为不透水的尼龙布, 围隔内外完全分隔. 植物大量种植计划于 2004 年 6 月底完成, 以后只进行了少量 沉水植物补种. 围隔内设 11 个采样点, 围隔外西五里湖水域设 3 个采样点作为对照, 分别对水体中总氮 $\mathrm{TN} 、 \mathrm{TP} 、 \mathrm{NH}_{4}-\mathrm{N} 、 \mathrm{NO}_{3}-\mathrm{N} 、 \mathrm{NO}_{2}-\mathrm{N} 、 \mathrm{PO}_{4}-\mathrm{P} 、 \mathrm{Chl} . a 、 \mathrm{COD}_{\mathrm{Mn}}$ 含量、透明度 $(\mathrm{SD}) 、$ 浮游植物与浮游动物数量和生物量 进行采样分析,每月采样一次. 时间段为 2004 年 1 月至 2005 年 12 月.

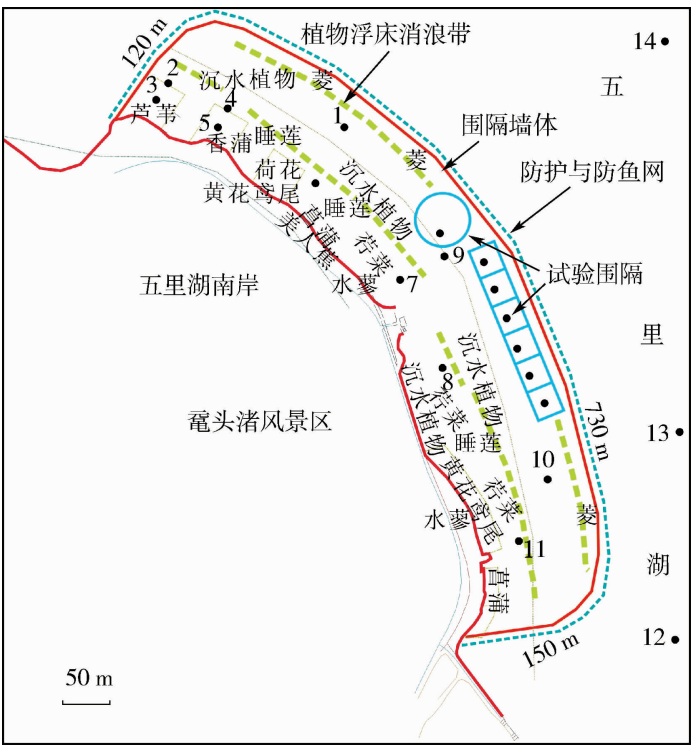

图 1 大型围隔内水生植物及采样点分布

Fig. 1 Distribution of aquatic plants inside large enclosure and sampling points
研究区域位置和样点分布如图 1, 环境背景以及 生态重建具体措施见陈开宁等报道 ${ }^{[1]}$.

数据统计与分析采用 SPSS10. 0 统计软件; 各参数 间相关分析采用 2 年中的所有样点数据进行分析; 浮 游植物多样性指数采用香浓 - 威纳指数 (ShannonWiener diversity index) 进行计算.

\section{2 结果与分析}

\section{1 生态重建对水质影响}

生态重建区围隔于 2004 年 3 月份建成, 区内种植 各种生活型水生植物, 并实施诸多生态重建措施, 详细 情况见陈开宁等报道 ${ }^{[1]}$. 从图 2 的结果可以看出, 围 隔内 (生态重建区域) 的 TN 、TP 含量比西五里湖区 (无 生态重建措施的对照区) 有显著下降,水体透明度也有 较大幅度提高 (图 2), 水环境质量明显改善. TP 含量 在 3 月份出现一个很高的峰值是五里湖周边的花卉施 肥和排污所致.

\section{2 生态重建对藻类生物量及种类组成的影响}

由图 3 可见,在生态恢复初期 (2004 年 3-6月) 围隔内藻类生物量平均比西五里湖 (对照区) 低 $45 \%$; 

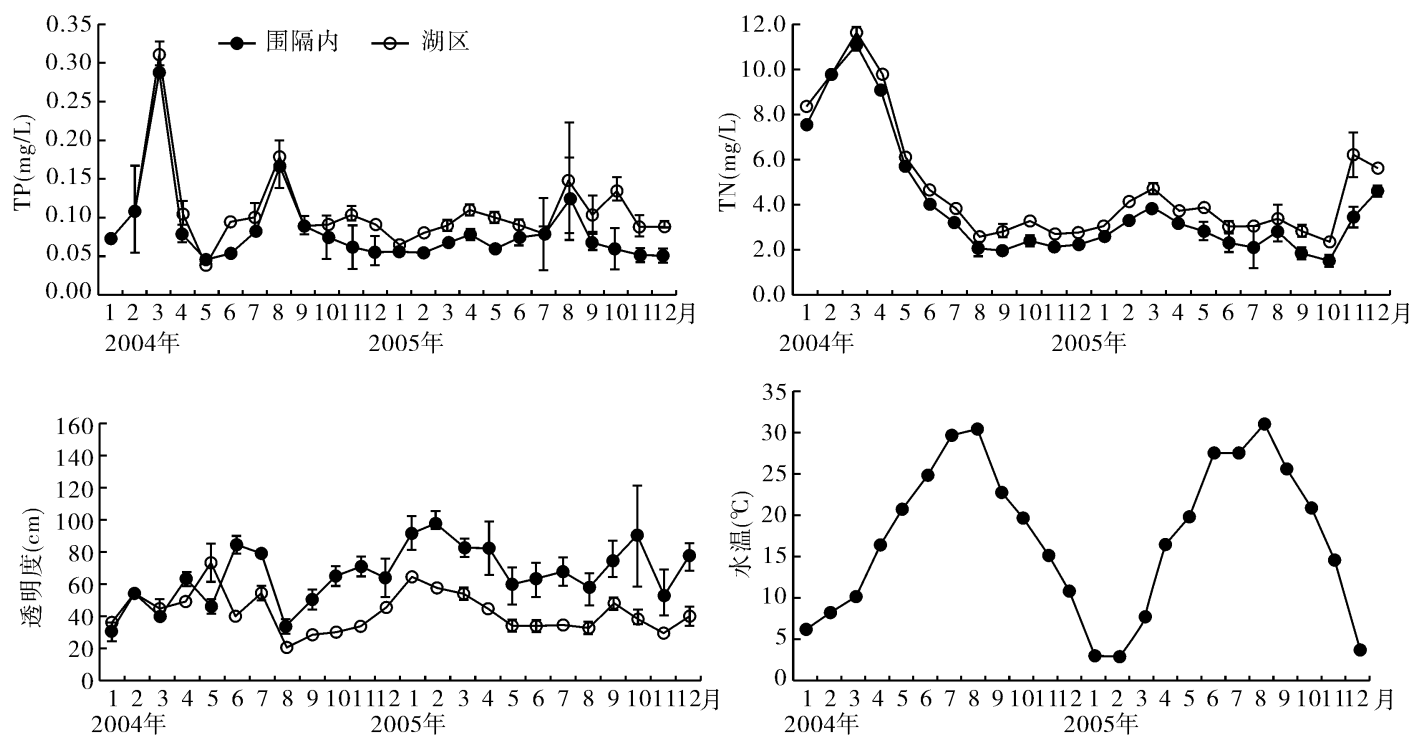

图 2 围隔内、西五里湖区水体总氮、总磷含量以及透明度、温度的变化

Fig. 2 Variety of TN, TP, secchi depth, water temperature inside enclosure and in west Wuli Lake

进人 7 月份后, 围隔内藻类大量增殖, 生物量远高于湖区, 高的生物量一直维持至 12 月份, 7-11 月围隔内 藻类生物量平均比对照区高 $224 \%$, 全年中仅 4 月份一个月明显低于湖区. 次年, 围隔内藻类生物量仅有 6 月份显著高于湖区,而 1-4 月份、8-10 月份和 12 月份均低于湖区 $44 \% 、 41 \%$ 和 $27 \%$,全年平均值低于湖 区 $23 \%$,表明生态重建区的第二年藻类生长受到一定程度抑制.

然而, 从第一年的结果看, 尽管生态重建区内种植了大量水生植物, 覆盖度达到 $35 \%-40 \%$, 水体氮磷 含量有较大幅度的下降, 水体透明度也被提高了近一倍 (图 2), 但是藻类却大量生长. 可见,生态重建的初 期, 虽然水质有所改善, 但藻类生物量并没有降低, 反而出现大量增殖现象; 而且, 改变的水体环境更有利于 蓝藻生长, 进入 7 月份, 蓝藻生物量不是逐步增加, 而是迅速增殖, 暴发式增长 (图 3 、图 4), 而湖区蓝藻则是 于 6-9 月份逐渐增加, 并逐步转为优势种群 (图 4). 围隔内藻类以及蓝藻的增殖方式可能是其生长的阻滞 力骤然消失或迅速减弱所致, 或者是促进力的增加.

生态重建措施对藻类生物量种类构成影响 的结果如图 4. 结果显示, 生态重建初期(2004 年 3-4月份) 围隔内和湖区的藻类以隐藻为优势 种, 占 $80 \%-88 \%$; 进人 5 月份, 优势种转变为绿 藻和硅藻, 分别占 $48 \%-55 \%$ 和 $38 \%-42 \%$. 至 6 月份,湖区的优势种不明显,围隔内以 $54 \%$ 的 裸藻占优势. 但 7 月份以后, 围隔内蓝藻大量生 长, 并骤然成为优势种类, $7 、 8$ 月占 $77 \%$ 和 $83 \%, 9-12$ 月占 $35 \%-44 \%$, 并使翌年全年中有 一定量的蓝藻于水体中生长.

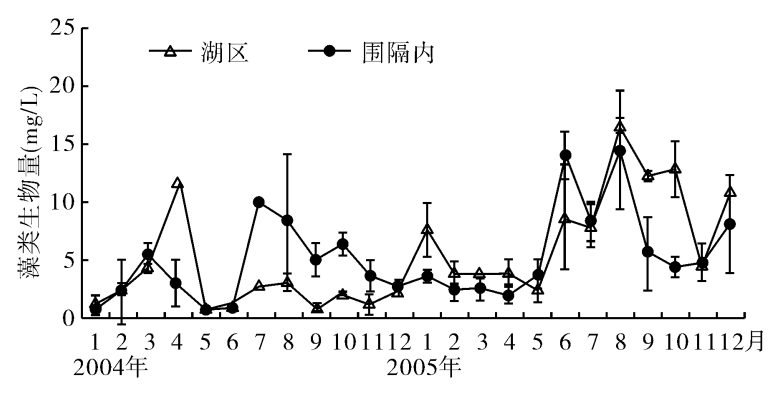

图 3 围隔内和西五里湖水域的藻类生物量的动态变化

2005 年(生态重建的第二年) $2-4$ 月, 围隔 Fig. 3 Variety of algal biomass inside enclosure and in west 内藻类的种类较多,优势种不明显; $5-7$ 月份以 Wuli Lake from 2004 to 2005 蓝藻占优势, 占 $53 \%-61 \% ; 8$ 月 -11 月转为绿 藻为优势种类, 占 $44 \%-70 \% ; 12$ 月优势种不明显. 而湖区于 2004 年 6 月份开始, 蓝藻生物量逐渐增加, 9 月份达最高，7、8、9 月蓝藻分别占 $22 \% 、 45 \% 、 54 \% ; 10$ 月份以后则以隐藻和硅藻占优势. 2005 年 1 月份情 
况较为特殊, 藻类和蓝藻生物量均较高, 其现象较难解释. 2-4 月份基本以隐藻和硅藻占优势, 5 月份以 后, 逐渐转变为绿藻为优势种类. 由此可见,生态重建改变了原五里湖以隐藻和硅藻为优势的状况. 此外, 监测数据也显示, 金藻仅在冬季出现.
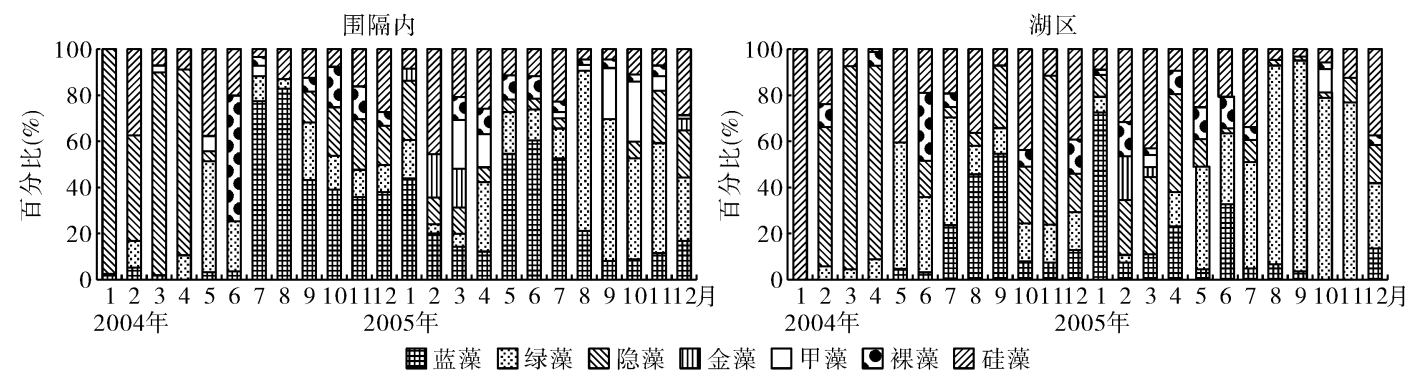

图 4 围隔内和五里湖对照区藻类生物量种类构成的动态变化

Fig. 4 Variety of biomass percent of different algae inside enclosure and in west Wuli Lake

从蓝藻组成结构方面看, 在生态重建第一年的冬末春初仅出现色球藻 (Chroococcus) 和蓝纤维藻 (Dactylococcopsis) ; 以束丝藻 (Aphanizomenon) 或颤藻 (Oscillatoria) 为优势种出现在温度相对低的春季、夏初和秋 冬季节; 微囊藻 (Microcystis) 主要发生在温度高的夏季 (图 5). 2004 年围隔内和湖区微囊藻为优势种类的 现象发生在 8-9 月份, 而 2005 年围隔内出现此现象仅 8 月份一个月,但湖区则从 7 月份至 10 月份维持了 此现象 4 个月. 此外, 秋季围隔内的蓝藻种类比湖区多, 出现了湖区没有的螺旋藻 ( Spirulina) 和项圈藻 (Anabaena). 由此可见,尽管生态重建的第一年没有控制住藻类生长, 反而使其中的蓝藻大量增殖; 但在第二 年,生态重建区的环境条件逐渐对藻类,包括其中的蓝藻以及微囊藻产生了抑制作用.

围隔内

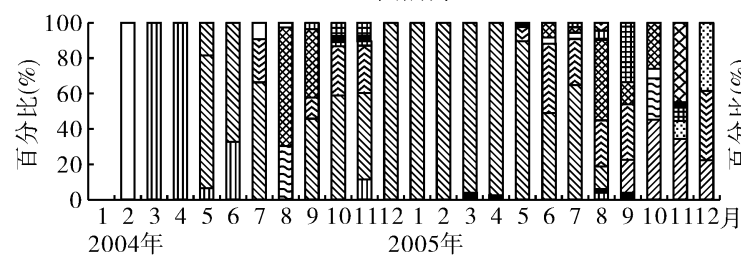

湖区

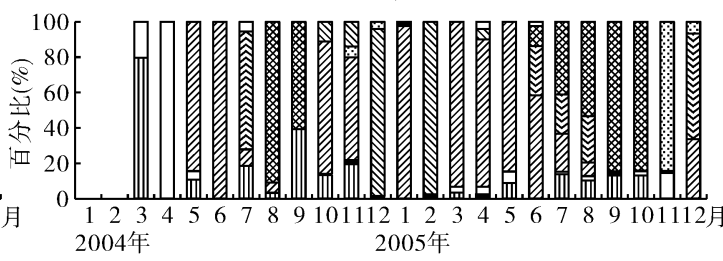

2004年 2005年

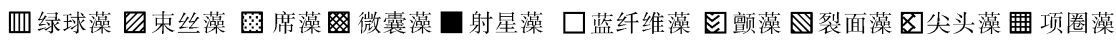

图 5 围隔内和五里湖对照区蓝藻生物量种类构成的动态变化

Fig. 5 Variety of biomass percent of different cyanobacteria inside enclosure and in west Wuli Lake

\section{3 藻类和蓝藻生物量与水质参数间相关性}

为了分析藻类以及其中蓝藻生长的驱动因素, 利用 SPSS 统计软件, 计算 2004 年 1 月 - 2005 年 12 月大 多数监测点次的藻类及蓝藻生物量与水质参数间相关性,结果见表 1 .

表 1 中结果表明,藻类总生物量与 $\mathrm{TN} / \mathrm{TP} 、 \mathrm{NO}_{3}-\mathrm{N}$ 呈极显著的负相关, 与 $\mathrm{TP} 、 \mathrm{NO}_{2}-\mathrm{N} 、$ Chl. $a$ 以及 $\mathrm{COD}_{\mathrm{Mn}}$ 呈极显著的正相关, 说明较低的 TN/TP 比值 (15.9-35.6, 平均 30.5) 可能有利于藻类生长, $\mathrm{NO}_{3}-\mathrm{N}$ 可能是 藻类生长所需的氮素营养来源; 另外, 藻类生物量的增加使水体 TP、Chl. $a$ 和 $\mathrm{COD}_{\mathrm{Mn}}$ 浓度升高.

蓝藻生物量与 $\mathrm{TN} / \mathrm{TP} 、 \mathrm{TN} 、 \mathrm{NH}_{4}-\mathrm{N} 、 \mathrm{NO}_{2}-\mathrm{N} 、 \mathrm{NO}_{3}-\mathrm{N}$ 及 $\mathrm{PO}_{4}-\mathrm{P}$ 呈极显著的负相关, 与藻类总生物量、Chl. $a$ 呈极显著的正相关, 其中蓝藻生物量与 TN/TP 的相关性高于藻类总生物量与 TN/TP 的, 说明较低的 TN/TP 比值更可能有利于蓝藻的生长; 同时也说明, 蓝藻的生长降低了水体中三态氮以及正磷酸盐, 总氮降低与蓝 藻生物量增加相伴随. 
表 1 藻类及蓝藻生物量与水质参数间相关性 $(n=293)$

Tab. 1 Correlations between algal biomass, cyanobacteria biomass and parameters of water quality $(n=293)$

\begin{tabular}{|c|c|c|c|c|c|c|c|c|c|c|c|}
\hline & Cyano. A & Algal Bio. & . TN/TP & $\mathrm{COD}_{\mathrm{Mn}}$ & Chl. $a$ & $\mathrm{TN}$ & $\mathrm{TP}$ & $\mathrm{PO}_{4}$ & $\mathrm{NH}_{4}$ & $\mathrm{NO}_{3}$ & $\mathrm{NO}_{2}$ \\
\hline $\begin{array}{c}\text { Cyano. } \\
\text { Sig. }\end{array}$ & 1.000 & & & & & & & & & & \\
\hline \multicolumn{2}{|c|}{ Algal Bio.0. $296^{* *}$} & 1.000 & & & & & & & & & \\
\hline Sig. & 0.000 & & & & & & & & & & \\
\hline $\mathrm{N} / \mathrm{P}$ & $-0.330^{* *}$ & $-0.258^{* *}$ & 1.000 & & & & & & & & \\
\hline Sig. & 0.000 & 0.000 & & & & & & & & & \\
\hline $\mathrm{COD}_{\mathrm{Mn}}$ & 0.088 & $0.477^{* *}$ & 0.044 & 1.000 & & & & & & & \\
\hline Sig. & 0.135 & 0.000 & 0.457 & & & & & & & & \\
\hline Chl. a & $0.301^{* *}$ & $0.420^{* *}$ & $-0.362^{* *}$ & $0.560^{* *}$ & 1.000 & & & & & & \\
\hline Sig. & 0.000 & 0.000 & 0.000 & 0.000 & & & & & & & \\
\hline $\mathrm{TN}$ & $-0.393^{* *}$ & -0.079 & $0.600^{* *}$ & $0.313^{* *}$ & 0.029 & 1.000 & & & & & \\
\hline Sig. & 0.000 & 0.176 & 0.000 & 0.000 & 0.620 & & & & & & \\
\hline $\mathrm{TP}$ & -0.089 & $0.248^{* *}$ & $-0.314^{* *}$ & $0.380^{* *}$ & $0.493^{* *}$ & $0.472^{* *}$ & 1.000 & & & & \\
\hline Sig. & 0.129 & 0.000 & 0.000 & 0.000 & 0.000 & 0.000 & & & & & \\
\hline $\mathrm{PO}_{4}$ & $-0.211^{* *}$ & -0.022 & 0.079 & -0.072 & -0.055 & $0.315^{* *}$ & $0.250^{* *}$ & 1.000 & & & \\
\hline Sig. & 0.000 & 0.706 & 0.175 & 0.222 & 0.349 & 0.000 & 0.000 & & & & \\
\hline $\mathrm{NH}_{4}$ & $-0.263^{* *}$ & -0.067 & $0.449^{* *}$ & $0.239^{* *}$ & 0.103 & $0.903^{* *}$ & $0.511^{* *}$ & $0.285^{* *}$ & 1.000 & & \\
\hline Sig. & 0.000 & 0.250 & 0.000 & 0.000 & 0.079 & 0.000 & 0.000 & 0.000 & & & \\
\hline $\mathrm{NO}_{3}$ & $-0.498^{* *}$ & $-0.280^{* *}$ & $0.516^{* * *}$ & 0.018 & $-0.227^{* *}$ & $0.467^{* *}$ & 0.007 & 0.029 & $0.206^{* *}$ & 1.000 & \\
\hline Sig. & 0.000 & 0.000 & 0.000 & 0.754 & 0.000 & 0.000 & 0.900 & 0.626 & 0.000 & & \\
\hline $\mathrm{NO}_{2}$ & $-0.267^{* *}$ & $0.514^{* *}$ & -0.076 & $0.287^{* *}$ & $0.159^{* *}$ & 0.100 & $0.281^{* *}$ & $0.232^{* *}$ & -0.017 & $0.147 *$ & 1.000 \\
\hline Sig. & 0.000 & 0.000 & 0.194 & 0.000 & 0.007 & 0.087 & 0.000 & 0.000 & 0.774 & 0.012 & \\
\hline
\end{tabular}

**表示相关性极显著

\section{4 藻类多样性指数的动态变化}

图 6 是围隔内和西五里湖区藻类多样性指数的变化与比较结果. 整体而言,生态重建并没有显著提高 围隔内藻类多样性,生态重建的第二年仅 1 月份、4 月份和 9-10 月份围隔内高于湖区的; 相反,湖区多样性 指数则多个月份显示较高, 超过 2.0. 从水质、水生植物生长与覆盖情况以及上述的结果看, 生态重建区域 的水环境比湖区有了大幅度的改善. 由此可见, 藻类多样性指数增加并不能完全反映水环境改善状况, 因 此, 在评价水环境质量方面, 单凭藻类多样性指数变化并不能准确反映水环境状况, 应该结合其他多种因素 进行综合评价.

\section{3 讨论}

浮游植物生长不仅受到光照、营养盐、温度、无机碳等非生物因素影响, 而且也受到浮游动物、食浮游生 物鱼类、水生高等植物以及微生物的生物多种因素的限制 ${ }^{[2]}$, 上行效应与下行效应理论 ${ }^{[3]}$ 较经典地描述它 们之间的作用关系.

从本研究的结果看, 尽管生态重建区 (围隔内) 栽种有大量水生高等植物,2004 年 6 月份的覆盖率已达 到 $35 \%$ 以上 ${ }^{[1]}$, 但是, 进人 7 月份后, 水生高等植物并没有对水体中藻类生长产生较大的抑制作用, 相反, 藻类生物量大大超过了无水生高等植物生长的湖区, 并且蓝藻水华大量暴发, 时间持续了近 3 个月. 生态 重建的第二年(2005 年), 水生高等植物覆盖率进一步增加, 达到 $55 \%$ 以上, 围隔内藻类生物量仅有 6 月份 显著高于湖区,全年中有 8 个月低于湖区, 蓝藻在水面形成漂浮水华现象仅出现夏季 8 月份中一周左右时 


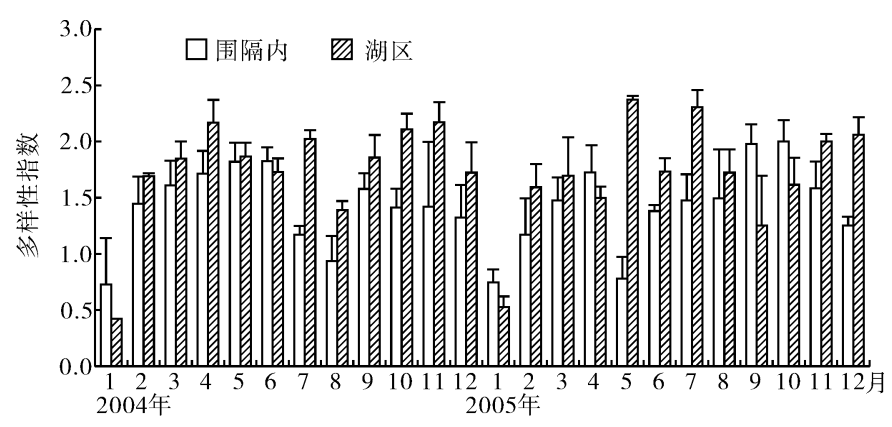

图 6 围隔内藻类多样性指数与湖区比较

Fig. 6 Shannon diversity index of phytoplankton species inside enclosure and in west Wuli Lake

间, 表现出水生高等植物对藻类有抑制作用, 但是, 藻类的全年平均生物量并没有显著降低. 那么究竟是什 么原因造成蓝藻大量暴发?

从水体营养盐变化的观测结果分析,2004 年 6-7 月围隔内氮含量没有增加, 反而有所下降,磷含量有 一定幅度上升,但并没有湖区增加的高, 而 7 月份藻类的生物量却比湖区高得多. 2005 年在藻类大量增殖 的 6 月份, 围隔内水体氮含量也没有增加, 磷有小幅度上升. 比较湖区而言, 从 2004 年 6 月份起,围隔内水 体中氮磷营养盐比湖区有显著下降,但没有对藻类生长生产较大抑制作用. 水体氮磷含量与藻类相关性分 析结果也显示, 水体氮磷含量与蓝藻生物量增加没有正相关关系, 只有 TP 与总藻类生物量存在正相关关 系. 这些结果表明,氮磷营养盐并不是围隔内蓝藻大量暴发的决定因素, 同时也说明上行作用力并没有通 常认为的强烈.

光照和温度对藻类生长亦有一定的影响. 从水下光照方面看, 围隔内水体透明度从 2004 年 6 月份开 始已有显著提高, 水下有效光合层增大,有利于水柱中藻类进行光合作用,增加水柱的初级生产力, 进而促 进藻类生长繁殖. 从水温方面看, 2004 年 7 月份水温升高至 $29.4^{\circ} \mathrm{C}$, 此时, 藻类生物量达到最高, 其中主要 由蓝藻构成; 而 2005 年水温上升的比 2004 年早, 于 6 月份即达到 $27.5^{\circ} \mathrm{C}$, 藻类生物量也相应地于 6 月份迅 速增加 (图 2 - 图 4). 因此, 温度上升也在一定程度上促进藻类大量增殖, 且 $27^{\circ} \mathrm{C}$ 以上的水温较适宜蓝藻大 量增殖. 但比较围隔与湖区两块水域表明, 藻类的暴发式增长还存在其他作用更为强烈的影响因素.

从营养链级作用或下行效应方面分析, 藻类的增长受到上一级的浮游动物限制, 其中大型植食性浮游 动物 (如一些枝角类和桡足类) 的作用较强 ${ }^{[3,4]}$. 从浮游动物动态变化方面看,2004 年 5 月份浮游动物生物 量较高, 出现一个峰值, 6 月份有大幅度下降, 至 7 月份围隔内浮游动物生物量已接近最低值, 特别是体型 较大的枝角类, 这种现象为围隔内藻类迅速增长提供了条件; 而湖区 7 月份的浮游动物又出现了一个峰值, 而且枝角类也较多, 藻类增长的幅度也较围隔内的小得多(图 3、图 7). 2005 年 6 月份围隔内浮游动物生物 量并没有降低, 但是, 枝角类浮游动物有较大下降, 这可能也是导致藻类迅速增长重要因素之一; 而湖区在 6 月份各类浮游动物生物量均有较大幅度降低, 藻类大量生长. 由此可见,下行作用力的迅速减弱或消失对 藻类大量暴发有显著的影响.

但是, 类似太湖的亚热带湖泊中的浮游动物对夏季浮游植物的牧食压力较小. 其原因为: (1) 夏季大型 甲壳类浮游动物生物量通常较低. 金琼贝等通过受控试验获得的结果表明, 枝角类、桡足类在水温达到 $30^{\circ} \mathrm{C}$ 以上时,数量开始大幅度下降 ${ }^{[5]}$. 太湖夏季 $7-8$ 月份平均水温通常超过 $30^{\circ} \mathrm{C}$ (图 2 ), 这可能是夏季浮 游动物数量减少的原因之一. 王如平和徐家铸对南京玄武湖浮游动物周年变化时发现,浮游动物数量夏、 秋季高于冬、春季,但其数量波动主要受原生动物、轮虫的影响, 桡足类、枝角类数量的高峰值主要出现在春 季的 4-5 月份, 夏季却很少 ${ }^{[6]}$. 类似的现象在贵州的红枫湖 ${ }^{[7]}$ 也出现过. 竞争和捕食相互影响被认为是 导致浮游动物群落演替的重要原因 ${ }^{[8]}$. 鱼类对大型浮游动物, 特别是对大型甲壳动物的捕食已从多方面得 到证实,特别是水温较高时,鱼类捕食量增加. 研究也表明,食浮游生物的鱼类在选择食物时, 首先选择的 是枝角类,而不是桡足类 ${ }^{[8]}$. (2) 亚热带湖泊中浮游动物体型偏向中小型 ${ }^{[9]}$. 黄祥飞通过对武汉东湖透明 

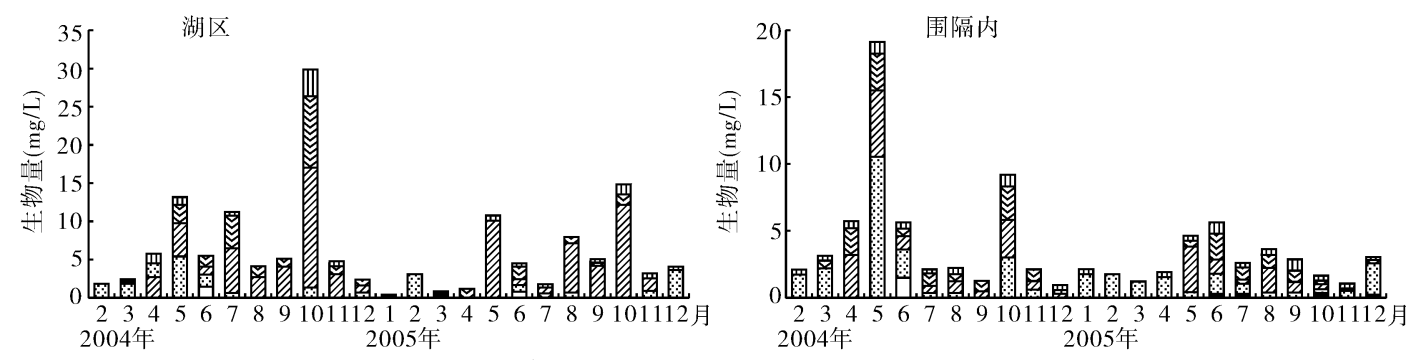

血无节幼体 国桡足类 $囚$ 枝角类 因轮虫 $\square$ 原生动物

图 7 各类浮游动物生物量的动态变化

Fig. 7 Variety in biomass of different kinds of zooplankton

溞 (D. hyalina) 和隆线溞一亚种 (D. carinata ssp.) 的研究发现, 这两种溞低温时培养的个体普遍大于高温 时培养的个体, 说明水温较高时可能导致个体小型化 ${ }^{[10]}$. 鱼类的捕食也导致浮游动物个体小型化. (3) 亚 热带湖泊的夏季水温高于温带湖泊, 有利于蓝藻生长, 特别是微囊藻, 这些藻类在自然水体中喜群聚生活, 不能被浮游动物所摄食利用, 而且还对枝角类有毒性作用, 增加了枝角类的死亡率 ${ }^{[11]}$. 从本研究结果看, 围隔内的水体从隐藻型转向蓝藻型后, 浮游动物生物量有较大幅度的下降, 而湖区的隐藻型、硅藻型或绿藻 型则对浮游动物生物量的影响较小.

此外, 围隔区和湖区浮游动物生物量分别在 5 月份和 10 月份出现两个峰值, 5 月的围隔区的浮游动物 对浮游植物总量有明显影响, 而 10 月份湖区的浮游动物的影响相对较弱, 这一现象可能是由于不同月份浮 游植物种类组成差异所致 (图 4、图 7).

藻类及蓝藻生物量与水质参数间相关性分析结果表明, 较低的 TN/TP 比值 (5-10 月份为 $15.9-$ 35.6 , 平均 30.5) 伴随着较高的藻类生物量, 尤其是蓝藻大量发生的时期, 这说明较低的 N/P 比值可能有利 于藻类和蓝藻生长. 这一结果与 Smith 的研究结果很接近 ${ }^{[12]}$, Smith 在分析世界 17 湖后认为, 形成蓝藻水 华的湖泊 TN/TP 比值不超过 29. 从另一方面看, 藻类量的增加可能由于细胞内一定的 N/P 比值而使水体 $\mathrm{TN} / \mathrm{TP}$ 比值由高下降. Xie et al 认为, 较低的 TN/TP 比值不是蓝藻水华产生的原因, 而是其导致的结果 ${ }^{[13]}$. 本研究结果显示, 较低的 TN/TP 比值既是蓝藻水华暴发的原因, 也是其作用的结果, 假如结果影响的作用 大, 随蓝藻生物量的增加, 水体的 TN、TP 应该是增加的. 从本研究的相关性分析结果看, 蓝藻生物量的变化 与 $\mathrm{TN}$ 呈极显著的负相关, 而与 TP 含量变化无关, TP 含量仅与藻类总生物量呈极显著的正相关, 说明 $\mathrm{TN}$ 的下降有利于蓝藻生长, TP 的增加并不是大量蓝藻暴发的主导因素, 因为在高 TN 时, 较高的 TP 并没有大 量蓝藻产生, TP 的增加仅促进藻类总生物量增加, 而 TN 的下降导致较低的 TN/TP 比值环境的出现. 此外, 随温度升高, 水体中反消化微生物作用增强, 可以降低水体 TN 含量; 同时, 沉积物中微生物活性增加, 以及 较高温度可能导致沉积物表面氧亏和 $\mathrm{pH}$ 值的增加 ${ }^{[14-16]}$, 从而促进沉积物磷的释放, 增加了水体 $\mathrm{TP}$ 含量, 这些又有利于水体 $\mathrm{N} / \mathrm{P}$ 比值降低和藻类大量生长. 因此, 较低的 $\mathrm{N} / \mathrm{P}$ 比值应该是蓝藻发生的主要原因之 一. 综上所述, 水体从高的 TN/TP 比值 $(36-212)$ 下降至较低的 TN/TP 比值 (16-36) 可能将促进蓝藻大量 暴发, 蓝藻生物量大量增加也可能由于其细胞内一定的 N/P 比值导致较低的水体 TN/TP 比值. 因此, 较低 的 TN/TP 比值既是蓝藻水华暴发的原因, 也是其作用的结果. 这一结论也是符合辨证法观点的.

此外,生态重建措施较大幅度地改善了水环境, 但并没有显著提高围隔内藻类多样性指数, 因此, 藻类 多样性指数并不能完全反映水环境改善状况, 在评价水环境质量方面需要结合其他多种因素进行综合 评估.

\section{4 结论}

(1) 湖泊生态重建初步措施 (以水生植被重建为主) 可以在较短时间内 (当年) 有效降低水体氮磷营养, 提高水体透明度, 但要想在较短时间内 (2 年内) 改变一个较大的水生态系统、较大幅度地降低藻类生物量, 特别是夏季, 是相当困难的; 通过 2 年的湖泊生态重建努力,仅使生态重建区浮游植物量出现了下降的趋 
势, 要实现湖泊生态系统从藻类占优势的浊水稳态转变为以水生高等植物占优势的清水稳态, 还需要进行 更长期努力.

(2) 氮磷营养盐对水体藻类总量增加有较大影响,但不一定是蓝藻大量暴发的决定因素,上行作用力 对蓝藻的控制 (bottom-up effort) 表现的较下行作用力 (top-down effort) 要弱.

(3) 较低的 TN/TP 比值既是蓝藻水华暴发的原因, 也是其作用的结果, 较低的 TN/TP 比值将可能有利 于蓝藻的大量暴发.

(4) 生态重建措施较大幅度地改善了水环境, 但在短时间内对藻类种类组成及藻类多样性指数 (Shannon index) 影响并不显著,因此,藻类多样性指数并不能完全反映水环境改善状况,在评价水环境质量方面 需要结合其他多种因素进行综合评价.

致谢: 兰策介、许海、吕洪顺、包先明等帮助完成野外采样以及部分室内样品分析; 陈非洲博士提出宝贵的修 改意见, 在此一并表示感谢.

\section{5 参考文献}

[1] 陈开宁, 包先明, 史龙新等.太湖五里湖生态重建示范工程一一大型围隔试验. 湖泊科学, 2006, 18 (2) : $43-53$.

[2] Paerl H W, Fulton R S, Moisander P H, Dyble J. Harmful freshwater algal blooms, with an emphasis on cyanobacterial. Sci World, 2001, 1: $76-113$.

[3] Carpenter S R \& Kitchell J F eds. The trophic cascade in lakes. Cambridge, Cambridge University Press, 1993.

[4] Carpenter S R, Kitchell J F, Hodgson J R. Cascading trophic interactions and lake productivity. BioScience, 1985,35 : $634-639$.

[5] 金琼贝, 盛连喜, 张 然. 温度对浮游动物群落的影响. 东北师大学报 (自然科学版), 1991, 4: 103 -111 .

[6] 王如平, 徐家铸. 南京玄武湖浮游动物的种类组成及其数量周年变动的研究. 海洋湖沼通报, 1990, 3: $42-49$.

７7］易 菊, 刘美珊, 潘 鸿. 红枫湖浮游动物的分布及周年变化研究. 贵州环保科技, 1998, 4(1): 12 -18 .

[8] 杨宇峰, 黄祥飞. 浮游动物生态学研究进展. 湖泊科学, 2000, 12 (1) : 82 - 89 .

[9] Jeppesen E, Søndergaard M, Mazzeo N et al, Lake restoration and biomanipulation in temperate lakes: relevance for subtropical and tropical lakes. In: Reddy $\mathrm{R}$ ed. Tropical eutrophic lakes: their restoration and management (in press).

[10] 黄样飞. 温度对透明溞和隆线溞一亚种发育及生长的影响. 水生生物学集刊, 1984, 8 (2): 207 -224 .

[11] 黄祥飞等, 武汉东湖浮游动物数量和生物量变动的研究. 水生生物学集刊, $1984,8(3): 345-358$.

[12] Smith V H. Low nitrogen to phosphorus ratios favor dominance by blue-green algae in lake phytoplankton. Science, 1983,221 : $669-71$.

[13] Xie L, Xie P, Li S, Tang H, Liu H. The low TN:TP ratio, a cause or a result of Microcystis blooms. Water Research, 2003, 37 : $2073-2080$.

[14] Ramm K, Scheps V. Phosphorus balance of a polytrophic shallow lake with the consideration of phosphorus release. Hydrobiologia, $1997, \mathbf{3 4 2} / \mathbf{3 4 3}: 43$ - 53.

[15] Rattray M R, Howard-Williams C, Brown J M A. Sediment and water as resources of nitrogen and phosphorus for submerged rooted aquatic macrophytes. Aqua Bot, 1991, 40: 225 - 237.

[16] Søndergaard M, Jensen J P, Jeppesen E. Role of sediment and internal loading of phosphorus in shallow lakes. Hydrobiologia, 2003,506 - 509: 135 - 145 . 